\title{
MOVING TOWARDS AN OPEN ARCHAEOLOGY: PROJECTS, OPPORTUNITIES AND CHALLENGES
}

\section{by Edeltraud Aspöck}

\begin{abstract}
Generally, open science practices are only slowly having an impact on mainstream archaeological practice. An exception is the open access to publications, which, together with open data and open methodologies may represent those practices most relevant for archaeological researchers. This article introduces a selection of archaeology projects that embrace and facilitate open science practices. Finally there will be a discussion of some of the questions and challenges the discipline is facing in its move towards an Open Archaeology.
\end{abstract}

Keywords: Archaeology; FAIR; ARIADNE; ARIADNEplus; Open Data; Open Methodology; Open Access; Open Source; barriers to Open Science

\section{AUF DEM WEG ZU EINER OFFENEN ARCHÄOLOGIE: PROJEKTE, CHANCEN UND HERAUSFORDERUNGEN}

Zusammenfassung: Im Allgemeinen haben Open Science-Praktiken nur langsam Auswirkungen auf die gängige archäologische Praxis. Eine Ausnahme bildet der offene Zugang zu Publikationen, der - zusammen mit offenen Daten und Methoden - zu den für Archäolog*innen wahrscheinlich wichtigsten offenen Praktiken zählt. Dieser Artikel stellt eine Auswahl von Archäologieprojekten vor, die offene wissenschaftliche Praktiken anwenden und fördern. Schließlich wird es eine Diskussion über einige der Fragen und Herausforderungen geben, denen sich die Disziplin aufihrem Weg zu einer Open Archaeology gegenübersieht.

Schlagwörter: Archäologie; FAIR; ARIADNE; ARIADNEplus; Open Data; Open Methodology; Open Access; Open Source; Hindernisse für Open Science

DOI: https://doi.org/10.31263/voebm.v72i2.3249

(c) Edeltraud Aspöck

Dieses Werk ist lizenziert unter einer

Creative-Commons-Lizenz Namensnennung 4.0 International 


\section{Contents}

1. Introduction: Scientific Openness in Archaeology

2. Open Archaeology in Austria: examples from the ÖAW

3. Discussion: Unresolved issues of Open Science in archaeology (and beyond)

4. Conclusions

\section{Introduction: Scientific Openness in Archaeology}

'Open Science is the practice of science in such a way that others can collaborate and contribute, where research data, lab notes and other research processes are freely available, under terms that enable reuse, redistribution and reproduction of the research and its underlying data and methods.' (FOSTER plus 2019). This Open Science (OS) definition by the FOSTER Plus project, a two-year EU-funded project that aimed to make OS research practices the norm, emphasises making scientific research a more collaborative endeavour as the main aim of the movement. To achieve this, research practices need to be more transparent, so that others are able to understand and to build on results, data and methodologies.

Some OS advocates are putting strong emphasis on the participation of all parts of society, amateur or professional, in collaborative scientific research (Woelfle and Olliaro 2011) and, for example, embrace the 'Citizen Science' movement. Others identify areas where improvement is necessary and create their visions of future research practices (Kraker et al. 2016). Hence, there are many ideas about what OS is (or could be) and any researcher - and in this case archaeologist - cannot act on all potential aspects of OS simultaneously but choices have to be made (Bosman and Kramer 2017).

Generally, except for the discussion of Open Access to publications, the topic of OS is only slowly reaching mainstream archaeology. Aside from articles in more specialist cultural heritage and digital archaeology journals, a relatively small number of articles have appeared in major archaeological journals. In 2012, a volume of the journal World Archaeology was dedicated to the discussion of 'Open Archaeology'. The editor's rationale for the volume was to bring the implications for archaeology of the socalled 'open' approaches to science to the attention of a wider audience of academic archaeologists (Lake 2012a). In his introduction Mark Lake emphasises the 'democratisation' of the production and consumption of information through OS approaches (Lake 2012b, 471). In 2015, in an edited volume on 'Open Source Archaeology' (Edwards and Wilson 2015a) 
OS practices were discussed more broadly too. But the overall topic of the latter volume is likely to be again addressing a smaller and more specialist audience of archaeologists. Nevertheless, these publications indicate that all archaeologists are starting to become aware of OS.

Discussions of OS in archaeology mainly revolve around open access to publications and open data, but also open methodologies, open standards and open source software are part of the debate. Citizen science projects are sometimes discussed as part of the OS realm too (e.g. Lake 2012). Generally, it can be seen that OS practices in archaeology develop at different speeds in different countries, depending highly on circumstances such as, for example, research funding policies and availability of data repositories. In an important statement the 'Open Science Interest Group' (OSIG) of the Society of American Archaeologists (SAA) has identified three elements of OS that can offer the maximum benefit for archaeological researchers: open access to publications, open data and open methods (Marwick et al. 2017, 8-11). These practices have been deemed relevant to reach the three aims of the Society of American Archaeologists, which 1. 'advances archaeological research and disseminates archaeological knowledge' 2. 'improves the practice of archaeology and promotes archaeological ethics', and 3. 'serves as a bond among archaeologists worldwide in all segments of the archaeological community'.

Open data means free access to datasets and in archaeology a wide range of data types are created as a result of different types of fieldwork and post-fieldwork analyses. Typically though, archaeological data collections would include spreadsheets, texts, graphics, photos, databases and GIS (Geographic Information System) files (Aspöck and Masur 2014; Hagmann 2018). Traditionally, most of these data would not get published, but in a published article or book the data would be summarised in tables and figures, and sometimes more complete information would be provided in appendices or supplements. The publication of written accounts of archaeological research, supported with summary tables and figures, has traditionally be seen as the completion of a piece of research. Data that form the basis for analysis were seen as unimportant after research has been written up and published. Hence, preservation and publication of these data signals a change in archaeological research culture.

This situation is somewhat different in countries where data archives have been installed at an early stage. In the United Kingdom, the 'Archaeology Data Service' (ADS) was established as early as 1996 and since then archaeological data have been deposited at the ADS for long-term preservation and can be accessed for re-use (Richards 2017). However, look- 
ing at Europe as a whole this is the exception (Corns et al. 2014, Wright and Richards 2018). In Austria, the Austrian Academy of Sciences has launched its repository ARCHE 'A Resource Centre for the HumanitiEs' (ARCHE) in 2017 to guarantee long-term preservation of research data from the Humanities, including archaeology, and the Phaidra repository at the University of Vienna has also started hosting archaeological datasets (Hagmann 2018; Phaidra).

Open methodology means that methods of data collection, analysis and visualisation are made available openly to serve as a reference and be available for reuse. This can include empirical methods (e.g. the details of preparing archaeological samples for scientific analysis) and computational methods, such as settings used for analysis, models and statistical methods. It has also been pointed out that FOSS, free and open-source software, is not just open software but it can also be seen as a repository of knowledge about the tool (Ducke 2012). Open methods are important to allow reproducibility of research, meaning to be able to repeat a study with the same materials and methods in order to achieve the same result. Whilst standard scientific publications communicate the methods that have been used, there is usually not enough space in a journal article to provide enough information to enable the repetition of a study. Open methods have developed after failures to reproduce the results of important studies in biomedicine, psychology, genomics and political science (Marwick et al. 2017).

In this article I will introduce a selection of projects which practice, facilitate and promote OS practices in archaeology by developing infrastructures, tools, standards and free datasets and hence represent 'Open Archaeology' approaches. In alignment with the FOSTER Plus definition and taking into account the recommendations from OSIG, we may define Open Archaeology as a collaborative archaeology, where publications, data, methods and other research processes are freely available under terms that enable reuse, redistribution and reproduction of the research and its underlying data and methods. However, moving towards an Open Archaeology is not only a question of technical possibilities, as there are a series of unresolved ethical and cultural issues. The final section of this paper will discuss some of these questions.

\section{Open Archaeology: selected projects from Austria}

In recent years progressive OS policies and special funding schemes (e.g. Open Research Data pilot program of the Austrian Science Fund (FWF)) 
of the main funding bodies of academic archaeology in Austria (e.g. FWF, National Foundation for Research, Technology and Development, European Union) have facilitated aspects of OS in archaeological projects. This section of the article will introduce projects where the author of this paper has been involved and which were located at the Austrian Academy of Sciences (ÖAW) or where the ÖAW has been a partner. This is by no means a comprehensive list of archaeological projects in Austria that embrace OS principles. The survey and discussion of such projects would certainly be a good idea for a future paper or project.

The EU infrastructure project ARIADNE (Advanced Research Infrastructure for Archaeological Data Networking in Europe) $)^{1}$ ran from 2013 to 2017 with the overall aim of integrating archaeological datasets (spread across European data archives and archaeological organisations (Niccolucci and Richards 2013; Aspöck and Geser 2014). Similar to a library catalogue the ARIADNE catalogue (ARIADNE portal) enables researchers to search for data that are relevant for their research and with relevant metadata about how to use that data (Figure 1). Via the ARIADNE portal more than 1.7 million datasets can be accessed, which are managed according to the FAIR principles (FAIR). The FAIR principles, published in 2016, are a set of guidelines on how to make data findable, accessible, interoperable and reusable: characteristics open data should have to be fit for reuse. It is possible to query the ARIADNE catalogue of datasets via keywords, but also via a map interface and a timeline. Additionally, but not less importantly, ARIADNE has created tools and services for archaeologists, which are free to use via the project homepage (ARIADNE services). This includes the ARIADNE Visual Media Service which supports easy publication and presentation of visual media on the web. The ARIADNE infrastructure is freely accessible for everyone via the internet. The infrastructure primarily aims at archaeologists, for whom it will be an important tool to discover data and selected tools for their research. Parts of the information provided will also be useful for citizens to deepen their knowledge about archaeological finds of a specific period or region.

Since 2019 the Horizon 2020 funded e-infrastructure project ARIADNEplus (2019-2022; ARIADNEplus) ${ }^{2}$ has followed up and widened the ARIADNE agenda. More datasets will be integrated into the infrastructure, increasing not only the quantity of data that will be available via the portal, but also the range of different types of archaeological data. Whilst ARIADNE was mainly focused on excavation, sites and monuments data, the new ARIADNEplus Data Infrastructure data will be enlarged by specialist data from, for example, epigraphy, remote sensing, palaeoanthropology, bioar- 
chaeology, environmental archaeology, results of material sciences, dating and so on. ARIADNEplus will provide more advanced tools for digital analysis and interpretation such as visualization, annotation, text mining and geo-temporal data management tools. The tools and data will be tested with innovative pilots that are carried out as part of the project. The web services will be integrated in the European Open Science Cloud and will enable the use of cloud-based Virtual Research Environments (VRE). The project is guided by the EU Open Science strategy, incorporating Open Access, the EU Open Data strategy and the FAIR data principles.

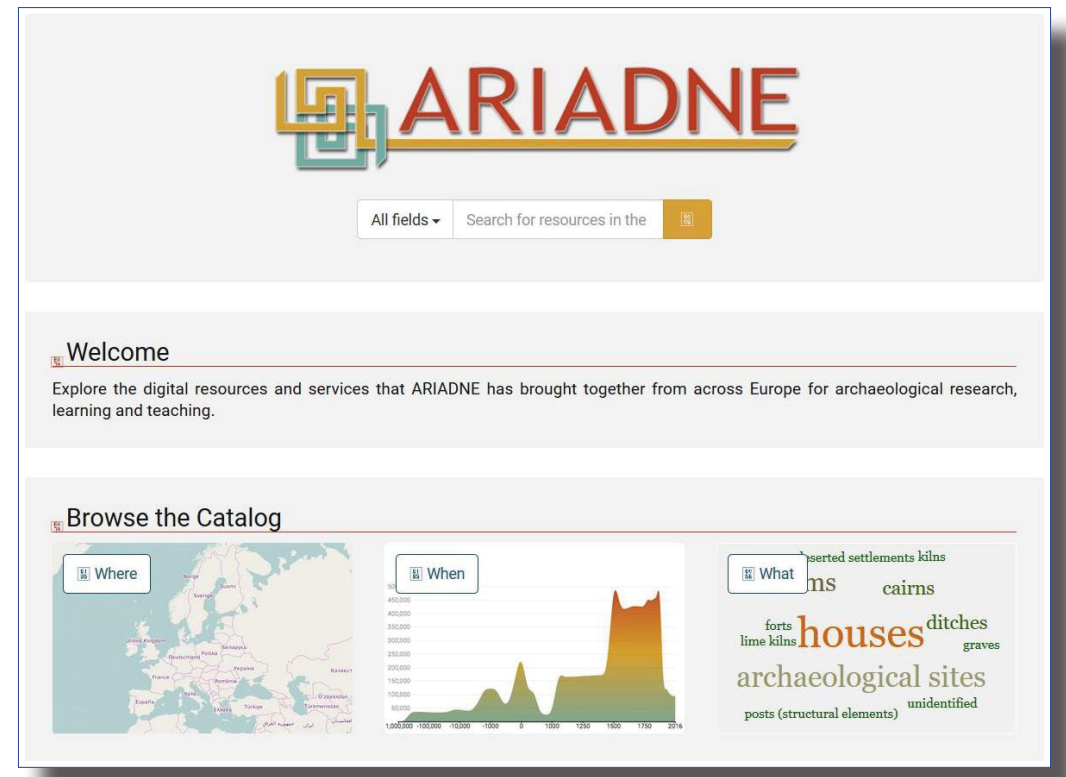

Fig. 1: The user interface of the ARIADNE catalogue allows to search for datasets via keywords, a timeline and a map service.

In the beginning of the ARIADNE project, topics such as data integration and data infrastructures were new to many archaeologists who took part in the project. This was due to big differences among ARIADNE partner countries relating to whether facilities for data long-term preservation and hence standards and policies for data management were in place. Consequently, a need to address basic data management issues as well as support the development of repositories and new datasets that adhere to standards was identified early (Corns et al. 2014; Wright and Richards 2018). As a result, the COST action SEADDA (2019-2022) was develo- 
ped and received funding from the EU (SEADDA). SEADDA stands for 'Saving European Archaeology from the Digital Dark Ages' and addresses the problem that most archaeological research is non-repeatable - at an excavation, most of the evidence is destroyed - and that the fragility of digital data may cause a lot of information about our cultural heritage to be lost. There is a lack of appropriate repositories for the archaeological domain and the SEADDA network includes archaeologists and computer scientists, who aim to create resources and share expertise for ensuring preservation of archaeological data within the participating countries. The aim of the project is to make archiving, dissemination and open access reuse of archaeological data a priority area.

Two projects at the Austrian Academy of Sciences (ÖAW) - at the Institute of Oriental and European Archaeology (OREA) in cooperation with the Austrian Centre for Digital Humanities (ACDH) - have developed out of ARIADNE. The 'Digitising Early Farming Cultures' project (DEFC) ${ }^{3}$ integrated information from Neolithic-period resources from Greece and Anatolia, including databases, publications and a pottery collection (Aspöck and Masur 2015; Andorfer et al. 2016; Štuhec et al. 2016). The 'DEFC App' is a site database which, due to its very granular data model, also allows integration of detailed information on finds. Hence, the application can be used to query typical finds from that period and region, some of which can also be viewed in 3D. 3D-models of pottery sherds from the Schachermeyr pottery teaching collection (Schachermeyr 1991) have been integrated and represent a resource for students and scholars alike.

In the DEFC project, 'open' applies to nearly all parts of the project. There is open access to data, which can be queried and downloaded via the application. Information about the creation of the application is available online via the 'Building the defc app' blog (Figure 2). The posts provide information about the methodology, workflows and tools used in the project. Most importantly, information about work processes that did not work out can also be found, helping others to avoid making the same errors. Furthermore, the source code of DEFC App is available on GitHub (DEFC App GitHub) and has already been reused for an online database on late Bronze Age cremation graves (Cremation Bronze Age Burials (CBAB App). The vocabulary of the thesaurus is also openly available for reuse in other projects, hence providing an open standard (Figure 2 ). The DEFC App can be used by scholars and students internationally for resource discovery (to get basic information, including publications about an archaeological site) and to familiarise themselves with typical finds from that period and region. Currently, the value of the application 
as an actual research dataset is tested in a case study of temporal-spatial distribution of finds (pottery types).

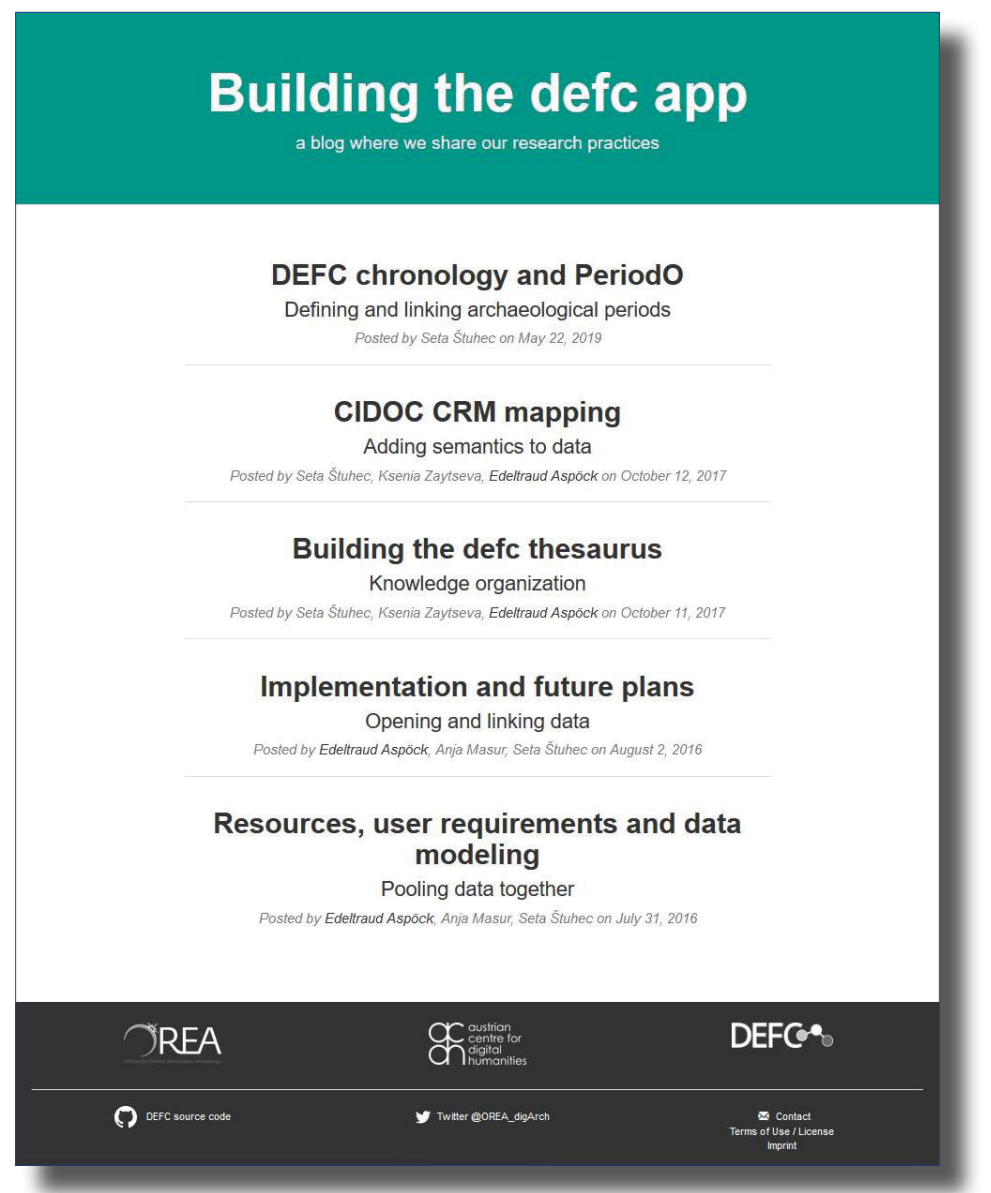

Fig. 2: Information about the workflows and tools that were used for creating the DEFC App are available via the project homepage. The blog also contains information about unsuccessful workflows, the reasons for that, and how it got finally resolved - which for many may also be very important information.

'A Puzzle in 4D'4 is the second project at the ÖAW (OREA in collaboration with $\mathrm{ACDH}$ ) that has developed out of ARIADNE. It deals with the resources from the Austrian long-term excavation project in Tell el-Daba in Egypt and runs from 2015-2020 (Bietak, 1996, Aspöck et al. 2015). Austrian excavations at Tell el-Daba have taken place since 1966 and, after 50 years 
of fieldwork, a huge and heterogeneous amount of digital and analogue resources such as photographs, plans, drawings and written documentation is held at the archive of OREA at the ÖAW. The overall aim of the 'A Puzzle in 4D' project is to prepare these resources for long-term archiving based on national and international standards and in accordance with open-access policies.

For the project, an innovative semantic workflow for the integration of data and metadata was developed (Aspöck et al forthcoming). Using the CIDOC CRM ontology (Doerr 2003) for cultural heritage documentation did allow the creation of the complex relationships needed for the data model and it enables the data to be encoded in a machine-readable format, hence making it findable and accessible and adding to its interoperability and reusability (FAIR). The documentation of the workflows (e.g. digitization of analogue resources, processing of digital resources for longterm archiving, metadata creation) will be made accessible via the project homepage at the end of the project (A Puzzle in 4D), providing guidelines for similar projects. This will be a useful resource, because generally little information is available about how to deal with the digitization of such huge resources from long-term excavation projects (Aspöck forthcoming). The code of the web application that will provide access to the digital resources is available via GitHub (A Puzzle in 4D GitHub). Parts of the digital resources will be freely available online for the research community and the interested public. However, access to a large part of the data will be restricted, because the resources in question are still under study. Hence, as in many other archaeology projects, there are limitations to the application of openness in this project.

\section{Discussion: Unresolved issues of Open Science in archaeology (and beyond)}

Especially regarding digital data, Open Science is intrinsically tied to the availability of technical solutions that enable openness. However, moving towards an Open Archaeology is not only a question of technical possibilities, there are a series of ethical and cultural issues involved too, many of which are unresolved and may not be restricted to archaeology alone.

Generally, since main funding bodies started pushing open access publication and archiving of research data in trusted repositories these two aspects of OS have already become a requirement for those who receive public funding. Hence, 'open' is not only philanthropically motivated but 
it may be a necessary strategy to carry out funded research (Edward and Wilson 2015b). Additionally, archaeology, cultural heritage, as well as other humanities subjects are under great pressure to justify their existence against the hard sciences, which are publicly perceived to be more important in respect to their 'impact' on society. Openness can be seen as a way to justify dedicating taxpayers' money to archaeology and the humanities and a redistribution to the public by making publicly funded research freely available. However, if we agree that openness is a good thing, are the archaeological discipline and academia actually ready for it?

Efforts in open archaeology, such as the detailed documentation of methodologies and putting effort into the preparation of archaeological data for long-term archiving and reuse, is a lot of work. However, academically such endeavours are not highly valued (compare Moore and Richards 2015, Beck and Neylon 2012, most papers in Lake 2012). Generally, the dominant mindset is that shared data is worth less than a final interpretation or synthesis. Most importantly, open data and open methodologies are not part of the criteria of traditional evaluation procedures for funding and academic positions, which until now have relied on paper-based publications and in particular monographs. Hence, archaeologists promoting and adhering to OS practices are at a disadvantage. Policies and academic culture would need to change to make OS practices worth the effort.

One solution would be to see data sharing as a form of publication (e.g. Moore and Richards 2015). New tools and techniques for proper referencing and citation of data have been developed and will improve citation (e.g. the DOI system). Funding bodies have started to require data management plans and archiving of data after the end of projects. Whilst deposited data may slowly increase because of these measurements, finished articles that are accompanied with a dataset are still rare in archaeology. Without a change of evaluation criteria no real move towards open archaeological data will be possible. The same argument applies to provision of open methodologies, open standards or open software.

Another problem related to sharing archaeological data is data hoarding. Excavation is a time-intensive process that is often carried out with insufficient funding and hence may come with high personal costs. This has led to a strong sense of data 'ownership' - excavators believe that they have the exclusive publication rights of 'their excavation data'. The publication rights are an asset of an archaeologist, in particular if something important or outstanding was found. One result of this is the hoarding of data. It is not uncommon that excavation data remains unpublished over 
decades or even never gets published, because the archaeologist does not have the resources to prepare the data for publication. Because excavations are destructive, i.e. the investigations cannot be repeated, this means that such information gets lost (see strong criticism of this practice by Eric Kansa from the US data repository and -publisher Open Context, Kansa 2012, 507). As a measure against this, there are efforts by national and international archaeological organisations to provide guidelines for how long data from excavations are allowed to be held back (Huggett 2015, 9). In Austria, the Austrian Federal Monuments Authority (BDA) requires the submission of a report and data about the most important results within three months of the end of an archaeological intervention and hence ensures that records are preserved (BDA 2018). Unfortunately, these data are not made openly available to archaeologists.

Ben Marwick et al. (2017) suggest that the tendency to hoard data could be changed by the idea of 'data stewardship', which promotes a view where researchers collect and share data on behalf of the scientific community and society. However, this again would not solve the problem of evaluations. It might therefore be necessary to consider changing publication practices in archaeology from the favoured single-authored publications to groups of authors publishing with the excavators as coauthors. $^{5}$

Another obstacle for data sharing in archaeology is that excavations usually produce very large numbers of resources and their preservation and preparation for archiving is expensive, and a substantial amount of work (again, with currently little reward for the excavator). For example, in the five-year project A Puzzle in 4D (see above) it will only be possible to prepare one part of the excavation resources from over 50 years of fieldwork at Tell-el Daba for digital archiving. The documentation of the workflows and methodologies is therefore important for future projects. However, it needs to be seen that new excavations also are connected with high costs, and Ray Moore and Julian Richards suggested it might be worth evaluating the expenses of data preparation for archiving versus the costs of carrying out new excavations (Moore and Richards 2015).

Generally, archaeology has many unpublished resources from fieldwork and it will not be possible to publish all of them in the traditional way, i.e. in the form of books or articles (Moore and Richards 2015; Richards 2017). Their preservation and preparation for digital archiving might be an alternative, but because of the high costs of this process it may be necessary to discuss whether it is acceptable to provide digital access to resources with little preparation for re-use (Moore and Richards 2015). 
This would mean more work for the archaeologists who want to use these resources, because before using them they would have to put effort into ordering and understanding the data. However, traditional analogue fieldwork archives were often not particularly 'rich' with documentation about the resources and on how to use the archive, but archaeologists had to work their way through the documentation of previous fieldwork projects. Making sense of legacy data, i.e. other peoples' documentation, was at the beginning of a research project and an important step to understand an archaeological site, the methodology and theoretical background of the excavators and their interpretation of the evidence (e.g. Frey forthcoming, Zaina forthcoming).

\section{Conclusions}

Currently, open access to publications, data and methodologies may be regarded as the OS practices most beneficial for archaeological researchers. Policies of the main funding bodies of academic archaeology support OS and collaborative research practices. They require open access publication and archiving of research data at the end of the project, which has increased application of OS practices in recently funded archaeology projects. Furthermore, funding has gone to projects that specifically embrace and facilitate OS practices by providing datasets, infrastructures, tools and standards. However, these projects provide somewhat of a contrast to mainstream archaeological approaches to sharing of data, methods and other research practices, which are still far more restrictive, being rooted in the historical development of the discipline. It will take some time to change these traditions. However, current funding policies are having an impact on those archaeologists who rely on funding and are getting used to OS research practices that way.

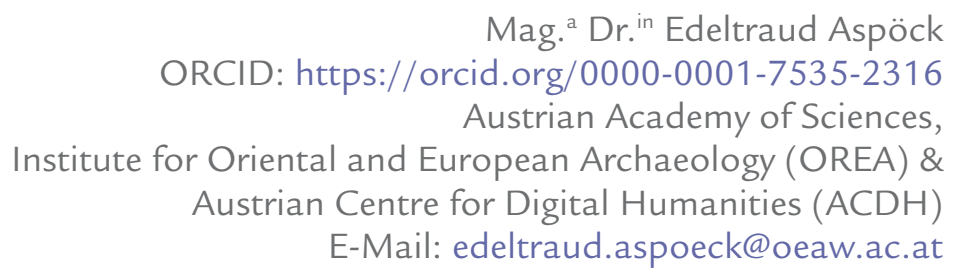

Mitteilungen der VÖB 72 (2019) Nr. 2: Open Science 


\section{References}

A Puzzle in 4D: https://4dpuzzle.orea.oeaw.ac.at/ (Last accessed 13 November 2019).

A Puzzle in 4D GitHub: https://github.com/acdh-oeaw/4dpuzzle (Last accessed 14 November 2019).

ADS 'Archaeology Data Service: https://archaeologydataservice.ac.uk/ (Last accessed 13 November 2019).

Andorfer, P.; Aspöck, E.; Ďurčo, M.; Masur, A.; Zaytseva, K. (2016). The DEFC-App: A Web-based Archaeological Data Management System for 'Digitizing Early Farming Cultures'. In: Digital Humanities 2016: Conference Abstracts. Kraków: Jagiellonian University \& Pedagogical University, 726-728.

ARCHE: https://arche.acdh.oeaw.ac.at/browser/ (Last accessed 13 November 2019).

ARIADNE portal: http://portal.ariadne-infrastructure.eu/ (Last accessed 13 November 2019).

ARIADNE services: portal.ariadne-infrastructure.eu/services (Last accessed 13 November 2019).

ARIADNEplus: https://ariadne-infrastructure.eu/ (Last accessed 13 November 2019).

Aspöck, E. and Geser, G. (2014). What is an archaeological research infrastructure and why do we need it? Aims and challenges of ARIADNE. In: Börner, W. and Uhlirz, S. (eds.). Proceedings of 18th Conference on Cultural Heritage and New Technologies (CHNT) 2013. Vienna: Stadtarchäologie, Museen der Stadt Wien, 1-10. http://www.chnt.at/wpcontent/uploads/Aspoeck_Geser_2014.pdf(Last accessed 03 July 2019). Aspöck, E. and Masur, A. (2015). Digitizing Early Farming Cultures. Customizing the Arches Heritage Inventory and Management System. In: Proceedings of Digital Heritage International Congress 2015, Granada, Spain, 463-464. https://doi.org/10.1109/DigitalHeritage.2015.7419549

Aspöck, E. and Masur, A. (2014). Archiving archaeological data in Austria (presentation held at the Digital Humanities Austria workshop on digital repositories), Vienna, 2 Dec 2014. https://www.slideshare.net/ ariadnenetwork/archiving-archaeological-data-in-austria-edeltraudaspck-anja-masur-oreaaw (Last accessed 13 November 2019).

Aspöck, E.; Hiebel, G.; Kopetzky, K.; Ďurčo, M. (forthcoming). A puzzle in 4D: Archiving digital and analogue resources of the Austrian excavations at Tell el Daba, Egypt. In: Aspöck, E.; Štuhec, S.; Kopetzky, K. and M. Kucera (eds.). Old excavation data - what can we do? Proccedings 
from workshop at $10^{\text {th }}$ ICAANE, Vienna April 2015. OREA Series, Vienna: Austrian Academy of Sciences Press.

Aspöck, E. (forthcoming). Old excavation data - what can we do? An introduction. In: Aspöck, E.; Štuhec, S.; Kopetzky, K. and Kucera, M. (eds.). Old excavation data - what can we do? Proccedings from workshop at $10^{\text {th }}$ ICAANE, Vienna April 2015. OREA Series, Vienna: Austrian Academy of Sciences Press.

Aspöck, E.; Kopetzky, K.; Horejs, B.; Bietak, M.; Kucera, M. and Neubauer, W. (2015). A puzzle in 4D digital preservation and reconstruction of an Egyptian palace. In: Proceedings of Digital Heritage International Congress 2015, Granada, Spain, 675-678. https://doi.org/10.1109/ DigitalHeritage.2015.7419596

Aspöck, E.; Štuhec, S.; Kopetzky, K. and Kucera, M. (eds.) (forthcoming). Old excavation data - what can we do? Proccedings from workshop at $10^{\text {th }}$ ICAANE, Vienna April 2015. OREA Series, Vienna: Austrian Academy of Sciences Press.

Beck, A. and Neylon, C. (2012). A vision for Open Archaeology. In: World Archaeology 44(4), 479-497. https://doi.org/10.1080/00438243.201 2.737581

Bietak, M. (1996). Avaris. The Capital of the Hyksos, London: British Museum Press.

Bosman, J. and Kramer, B. (2017). Defining Open Science Definitions. https://im2punt0.wordpress.com/2017/03/27/defining-open-science-definitions/ (Last accessed 13 November 2019).

Bundesdenkmalamt (2018). Richtlinien für archäologische Maßnahmen, 5. Fassung, 1. Jänner 2018. https://bda.gv.at/publikationen/standards-leitfaeden-richtlinien/richtlinien-fuer-archaeologische-massnahmen/ (Last accessed 13 November 2019).

CBAB (Cremation Bronze Age Burials) App: https://cbab.acdh.oeaw. ac.at/ (Last accessed 13 November 2019).

Corns, A.; Kennedy, L. and Štular, B. (2014). Impressions from the ARIADNE community: Slovenia and Ireland, Two Perspectives on Archaeology Data. In: ARIADNE. The Way forward to digital archaeology in Europe, 83-89. https://www.slideshare.net/ariadnenetwork/ariadne-the-wayforward-to-digital-archaeology-in-europe (Last accessed 14 November 2019).

DEFC (Digitizing Early Farming Cultures) App: https://defc.acdh.oeaw. ac.at/ (Last accessed 13 November 2019).

DEFC App GitHub: https://github.com/acdh-oeaw/defc-app (Last accessed 14 November 2019). 
Doerr, M. (2003): The CIDOC CRM - an Ontological Approach to Semantic Interoperability of Metadata. Al Magazine 24(3), 75-92. https:// doi.org/10.1609/aimag.v24i3.1720

Ducke, B. (2012). Natives of a connected world: free and open source software in archaeology. In: World Archaeology 44(4), 571-579. https:// doi.org/10.1080/00438243.2012.743259

Edwards, B. and Wilson, A.T. (eds.) (2015a). Open Source Archaeology: Ethics and Practice. Berlin: De Gruyter. https://doi.org/10.1515/9783110440171 Edwards, B. and Wilson, A.T. (2015b). Open Archaeology: Definitions, Challenges and Context. In: Edwards, B., Andrew T. Wilson (eds.). Open Source Archaeology: Ethics and Practice, Berlin: De Gruyter, 1-5. https://doi.org/10.1515/9783110440171-002

FAIR: https://www.force11.org/group/fairgroup/fairprinciples (Last accessed 14 November 2019).

FOSTER Plus (2019): FOSTER plus (Fostering the practical implementation of Open Science in Horizon 2020 and beyond) project, Open Science definition. https://www.fosteropenscience.eu/foster-taxonomy/ open-science-definition (Last accessed 14 November 2019).

Frey, J. (forthcoming). The ARCS Project: A “Middle Range" Approach to Digitized Archaeological Record. In: Aspöck, E.; Štuhec, S.; Kopetzky, K. and Kucera, M. (eds.) (forthcoming). Old excavation data - what can we do? Proccedings from workshop at $10^{\text {th }}$ ICAANE, Vienna April 2015. OREA Series, Vienna: Austrian Academy of Sciences Press.

Hagmann, D. (2018). Überlegungen zur Nutzung von PHAIDRA als Repositorium für digitale archäologische Daten. In: Mitteilungen der Vereinigung Österreichischer Bibliothekarinnen und Bibliothekare 71(1), 53-69. https://doi.org//10.31263/voebm.v71i1.1974

Huggett, J. (2015). Digital Haystacks: Open Data and the Transformation of Archaeological Knowledge. In: Edwards, B., Andrew T. Wilson (eds.). Open Source Archaeology: Ethics and Practice, Berlin: De Gruyter, 6-29. https://doi.org/10.1515/9783110440171-003

Kansa, E. (2012). Openness and archaeology's information ecosystem. In: World Archaeology 44(4), 498-520. https://doi.org/10.1080/004382 43.2012.737575

Kraker, P.; Dörler, D.; Ferus, A.; Gutounig, R.; Heigl, F.; Kaier, C.; Rieck, K.; Šimukovič, E.; Vignoli, M.; Aspöck, E.; Dennerlein, S.; Enkhbayar, A.; McNeill, G.; Schmidt, N.; Steinrisser-Allex, G.; Wandl-Vogt, E. (2016). The Vienna Principles: A Vision for Scholarly Communication in the 21st Century. Zenodo. https://doi.org/10.5281/zenodo.55597 Lake, M. (ed.) (2012). Open Archaeology. World Archaeology 44(4). 
Lake, M. (2012). Open Archaeology. In: World Archaeology 44(4), 471478. https://doi.org/10.1080/00438243.2012.748521

Marwick, B.; d'Alpoim Guedes, J.; Barton, C. M.; Bates, L. A.; Baxter, M.; Bevan, A.; Bollwerk, E. A.; Bocinsky, R. K.; Brughmans, T.; Carter, A. K.; Conrad, C.; Contreras, D. A.; Costa, S.; Crema, E. R.; Daggett, A.; Davies, B.; Drake, B. L.; Dye, T. S.; France, P.; Fullagar, R.; Giusti, D.; Graham, S.; Harris, M. D.; Hawks, J.; Health, S.; Huffer, D.; Kansa, E. C.; Kansa, S. W.; Madsen, M. E.; Melcher, J.; Negre, J.; Neiman, F. D.; Opitz, R.; Orton, D. C.; Przstupa, P.; Raviele, M.; Riel-Savatore, J.; Riris, P.; Romanowska, I.; Smith, J.; Strupler, N.; Ullah, I. I.; Van Vlack, H. G.; VanValkenburgh, N.; Watrall, E. C.; Webster, C.; Wells, J.; Winters, J. and Wren, C. D. (2017). Open science in archaeology. In: SAA Archaeological Record 17(4), 8-14. http://eprints.gla.ac.uk/148887/ (Last accessed 14 November 2019).

Niccolucci, F. and Richards, J.D. (2013). ARIADNE: Advanced Research Infrastructure For Archaeological Dataset Networking in Europe. In: International Journal of Humanities and Arts Computing 7(1-2), 70-88. https://doi.org/10.3366/ijhac.2013.0082

PHAIDRA University of Vienna: https://phaidra.univie.ac.at/ (Last accessed 14 November 2019).

Ray, M. and Richards, J.D. (2015). Here Today, Gone Tomorrow: Open Access, Open Data and Digital Preservation. In: Edwards, B., Andrew T. Wilson (eds.). Open Source Archaeology: Ethics and Practice, Berlin: De Gruyter, 30-43. https://doi.org/10.1515/9783110440171004

Richards, J.D. (2017). Twenty Years Preserving Data: A View from the UK. In: Advances in Archaeological Practice 5(special issue 3), 227-237. https://doi.org/10.1017/aap.2017.11

Schachermeyr, F. (1991). Sammlung Fritz Schachermeyr: Die neolithische Keramik Thessaliens. Aus dem Nachlaß bearbeitet von Eva Alram-Stern, Veröffentlichungen der Mykenischen Kommission 13, Vienna: Academy of Sciences.

Štuhec, S.; Aspöck, E.; Masur, A.; Andorfer, P. and Zaytseva, K. (2016). Putting 3D models into context. Schachermeyr pottery collection and the DEFC app. In: Proceedings of the $8^{\text {th }}$ International Congress on Archaeology, Computer Graphics, Cultural Heritage and Innovation 'ARQUEOLÓGICA 2.0' in Valencia, Spain, Sept. 5-7, 2016, 449-451. https://doi.org/10.4995/arqueologica8.2015.4155

SEADDA: https://www.cost.eu/actions/CA18128/\#tabs|Name:overview (Last accessed 14 November 2019). 
Woelfle, M.; Olliaro, P. and Todd, M. H. (2011). Open science is a research accelerator. Nature Chemistry 3(10), 745-748. https://doi. org/10.1038/nchem.1149

Wright, H. and Richards, J.D. (2018). Reflections on Collaborative Archaeology and Large-Scale Online Research Infrastructures. In: Journal of Field Archaeology 43(supp. 1), 60-67. https://doi.org/10.1080/009 34690.2018.1511960

Zaina, F. (forthcoming). Back to the Archive: The Challenge of Old Excavation Data from Ancient Mesopotamia. In: Aspöck, E.; Štuhec, S.; Kopetzky, K. and Kucera, M. (eds.). Old excavation data - what can we do? Proccedings from workshop at 10 th ICAANE, Vienna April 2015. OREA Series, Vienna: Austrian Academy of Sciences Press.

1 ARIADNE has been funded under the European Commission's $7^{\text {th }}$ framework programme, contract no. FP7-INFRASTRUCTURES-2012-1-313193.

2 ARIADNEplus is funded by the European Commission's Horizon 2020 programme, contract no. H2020-INFRAIA-2018-1-823914.

3 The 'Digitising Early Farming Cultures' project (DEFC) has been funded by the Austrian National Foundation for Research, Technology and Development (contract no. ACDH 2014/22) and the ARIADNE project.

4 The 'A Puzzle in 4D' (4DP) project received funding from the National Foundation for Research, Technology and Development (contract no. $\mathrm{DH}$ 2014/12) and it has also been supported by the ARIADNE project.

5 I want to thank the anonymous reviewer for this suggestion. 